\title{
Milestones in
}

\section{managed care pharmacy}

\author{
Susan Cantrell, RPh, CAE, and Cynthia Reilly, BSPharm, MS
}

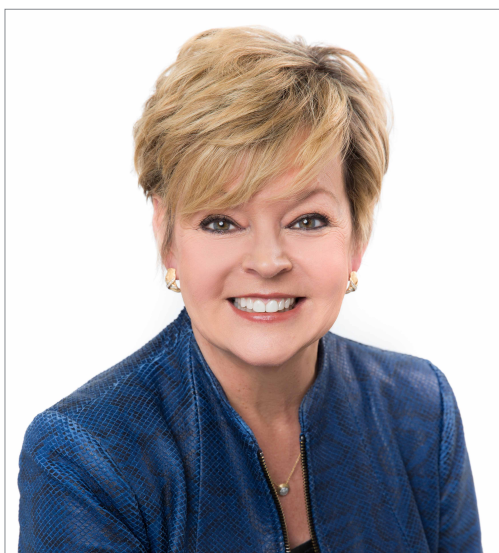

Susan Cantrell, RPh, CAE

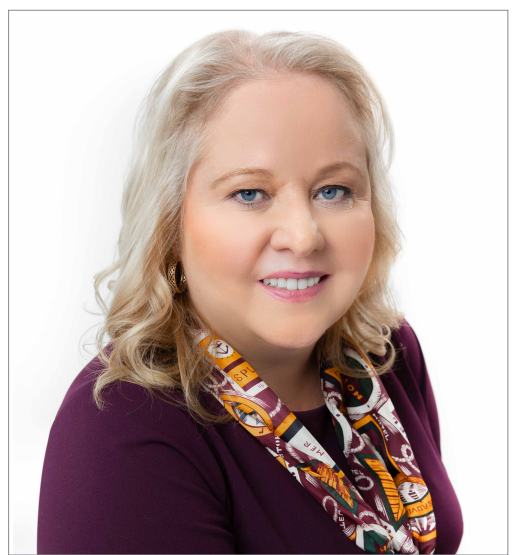

Cynthia Reilly, BSPharm, MS

\section{SUMMARY}

Managed care pharmacy has a relatively short history, but one that is defined by significant achievements. Since the late 1960s, managed care pharmacists have applied their unique skills to formulary management, clinical programs, benefit design, and contract negotiations to support patient access to life-saving therapies, while also ensuring cost-effective use of limited health care resources. Key milestones include establishing the pharmacy benefit as an essential component of the U.S. health care system, launching the Medicare Part D program, and expanding medication therapy management services. The year 2020 brings another milestone-the 25th anniversary of AMCP's flagship publication, the Journal of Managed

\section{Author affiliations}

Susan Cantrell, RPh, CAE, Chief Executive Officer, and Cynthia Reilly, BSPharm, MS, Chief Operating Officer, AMCP, Alexandria, VA.

\section{AUTHOR CORRESPONDENCE: Susan Cantrell, 703.684.2645, scantrell@amcp.org}

J Manag Care Spec Pharm. 2020;26(11):1379-83

Copyright $(2020$, Academy of Managed Care Pharmacy. All rights reserved.

Care + Specialty Pharmacy. This year also serves as an inflection point. As managed care pharmacy professionals prepare for change and the challenges ahead-including the imperative to address the rising costs of health care and health disparities-the use of evidence, utilization management strategies, and innovation will support our continued success.
The year 2020 marks the 25th anniversary of the launch of the Journal of Managed Care + Specialty Pharmacy (JMCP). This important milestone in managed care pharmacy's history has been recognized by the publication of a series of articles documenting the changes to the journal and to the profession in the last 25 years, along with a newly defined mission for JMCP to advance science, expertise, and evidence-based decision making to improve patient health through access to high-quality, cost-effective medications and other therapies.

This year also signifies an inflection point in managed care pharmacy and health care more broadly. MerriamWebster defines an inflection point as "a moment when significant change occurs or can occur."1 Few would argue that 2020 does not represent such a moment. As health professionals, all of us have been challenged professionally and personally by COVID-19. In short order, we have made critical adjustments to provide more care via telehealth, ensure uninterrupted access to medications for chronic diseases, and prepare for future vaccines and treatments to tame this pandemic. While the events of 2020 are unprecedented, AMCP and its members have 
a history of capably rising to meet new challenges. Looking back on the successes of the past may provide lessons on confronting the challenges that lie ahead.

\section{A Look Back}

The payment and delivery of pharmacy benefits have been transformed over the last 4 decades. This transformation was brought about by myriad factors, including legislative actions, various judicial decisions, marketplace competition among health insurers, and advances in health information and technology. One of the most notable factors is the evolution of the managed care pharmacy industry, which was spurred by visionary leaders focused on ensuring patient access to affordable medications.

Some consider the managed care pharmacy genesis to be the 1968 founding of the nation's first pharmacy benefit manager, Pharmaceutical Card System (PCS, later Advance PCS). The passage of the Health Maintenance Organization (HMO) Act of 1973, signed into law by President Richard Nixon, further catalyzed the role of managed care in the U.S. health care system and, along with it, the importance of managed pharmacy benefits. ${ }^{2}$ HMOs required the expertise of pharmacists with unique skills in areas such as evaluating evidence, developing formularies and clinical programs, optimizing patient outcomes, designing benefits, and negotiating contracts. It was from these emerging practice settings that 8 pharmacy leaders would go on to conceptualize and launch AMCP in the late 1980s.

The managed care pharmacy industry grew steadily in the 1980s and 1990s as pharmacy benefits became widely accepted as a vital component of comprehensive health care benefits. A 1999 article in JMCP described how United HealthCare, then providing health benefits for 13 million Americans, consolidated its pharmacy benefits after acquiring another managed care organization to rein in double digit annual growth in drug expenditures while also improving patient and physician satisfaction. ${ }^{3}$

Just a few years later, managed care pharmacy had another opportunity to demonstrate the profession's ability to improve outcomes and reduce costs when the Medicare Part D benefit was established under the 2003 Medicare Prescription Drug, Improvement, and Modernization Act. Yet, as the legislation neared passage, there was significant public skepticism. ${ }^{4}$ While there was public support for the concept of providing drug coverage, $43 \%$ of seniors said that the specific plan outlined in the legislation would have no effect and nearly a quarter believed that it would make things worse. Further, the Congressional Budget Office had estimated that the cumulative 10-year cost of the Part D program would be nearly $\$ 400$ billion. ${ }^{5}$ In fact, time demonstrated that actual costs were $30 \%$ less than expected. ${ }^{6}$ Experts have attributed the lower cost of the program to many variables, including the use of generic drugs when appropriate, competition among plans, and lower initial enrollment than expected. While the exact contribution of these and other factors is a matter of speculation, the effect of drug utilization management tools and other managed care pharmacy strategies cannot be refuted.

In a recent JMCP article, Caldwell and Edgar (2020) described their critical roles leading divisions within the Centers for Medicare \& Medicaid Services (CMS) that were charged with developing program rules and implementing, evaluating, and initiating contracts with plans in the mere 2 years and 23 days between passage of the law and the January 2006 launch of the program. ${ }^{7}$ The program's successful launch quelled much of the initial skepticism among beneficiaries and the broader public. Throughout the Part D benefit's almost 15-year history, managed care pharmacists have played essential roles in optimizing the program and driving access, outcomes, and cost-effectiveness for Medicare beneficiaries.

Satisfaction with Medicare Part D has grown over time, spurred in part by the addition of medication therapy management (MTM) services. A 2018 survey of Medicare beneficiaries indicated that $63 \%$ reported that they would recommend the service to another, and $41.7 \%$ rated recent MTM services as very good or excellent. ${ }^{8}$ The research also identified opportunities to improve the Standardized Format-the written summary provided to beneficiaries following an MTM encounter. Recommendations included enhancing the patient drug list by adding information on drug interactions and side effects. Importantly, roughly one-third of respondents (34.8\%) recommended the inclusion of information about alternative, less expensive medications in the same drug class. AMCP participated in and shared the results of this study-the largest evaluation of beneficiary preferences to date-with staff at CMS in response to the agency's February 2020 request for recommendations to improve the Standardized Format. ${ }^{9}$

\section{Challenges Ahead}

First described after managed care pharmacy's establishment, the so-called triple aim of health care-improving the experience of care, improving the health of populations, and reducing per capita costs-serves as its contemporary underpinning. ${ }^{10}$ Managed care pharmacy professionals employ a variety of strategies to ensure that patients have access to safe and affordable medications. These strategies-collectively referred to as utilization management-include, but 
are not limited to, formularies, prior authorization (PA), step therapy, drug utilization review, quantity management, and site of service steerage. ${ }^{11}$ In spite of evidence demonstrating the effectiveness of these measures and the importance of curbing the ever-increasing cost of health care in the United States, efforts to eliminate or undermine utilization management continue. ${ }^{12}$

Prior authorization (PA) is perhaps the most often misunderstood and mischaracterized utilization management tool. PAs help improve patient outcomes by encouraging the use of therapies that have evidence of efficacy and safety and that also provide the best value. Some critics argue that PA practices disregard important patient information, are ineffective in reducing overall health care costs, and do not improve quality of care..$^{13}$ Yet evidence suggests an important role for PA and other managed care pharmacy strategies, such as generic and therapeutic substitution and drug utilization review, in reducing costs while also improving patient safety and outcomes. A 2019 study by the U.S. Government Accountability Office (GAO) evaluated 52 peer-reviewed studies that examined the use of pharmacy benefit managers and efforts to manage drug expenditures and utilization in Medicare Part D..$^{14}$ GAO's review included a subset of studies focused on the effect of utilization management strategies. The review identified several studies in which these services were associated with financial savings and reduction in the use of potentially harmful drugs.

Utilization management tools, including PA, have been used successfully to reduce or eliminate inappropriate prescribing of opioids in managed care populations. Garcia et al. (2014) described the use of PA within a state Medicaid program to reduce the utilization and costs associated with long-acting opioid analgesics. ${ }^{15}$ A retrospective claims-based analysis demonstrated that the implementation of a PA process that imposed dose limits and identified preferred, less costly agents resulted in a significant overall decrease in opioid class use and lower per-member-per-month expenditures for those patients who required opioids.

Despite evidence supporting the effectiveness of PAs and other utilization management tools, efforts by state and federal legislatures, health care providers, medical societies, and others to thwart their use continue unabated. A state law passed in Arkansas provides an example of these efforts. The Arkansas law, passed in 2015, aims to regulate how pharmacy benefit managers contract with pharmacies under health plans governed by the Employee Retirement Income Security Act. The Pharmaceutical Care Management Association (PCMA) challenged this law, and after a federal appeals court ruled in PCMA's favor, the state of Arkansas appealed to the Supreme Court. AMCP filed a brief of amicus curiae in the case, appealing to the Court to uphold the lower court's ruling. ${ }^{16}$ AMCP's interest in this case is to support its members' ability to use managed care pharmacy strategies in employer-sponsored plans.

Managing the high cost of new and innovative therapies is a challenge for managed care pharmacy and the broader U.S. health care system. By 2023, the country's medication spend is expected to rise to $\$ 420$ billion, fueled predominantly by new products. ${ }^{17} \mathrm{AMCP}$ and its members will continue to focus on identifying solutions to address the rising costs of pharmaceuticals, such as implementing value-based contacting models that incentivize value over volume. Exploration of new payment models will also be critical, especially for curative therapies where costs are borne by an initial payer, but reductions in total cost of care are realized over time and often across several payers, as patients change health plans. Identifying how to best manage the cost of these therapies will likely require a new way of thinking about payment, such as through performancebased payment, milestone-based contracts, or annuity payments, as discussed at the AMCP Partnership Forum: Designing Benefits and Payment Models for Innovative High-Investment Medications in 2018. ${ }^{18}$

The importance of evidence is highlighted by the much anticipated COVID-19 therapies in the pipeline. As of September 2020, more than 700 unique compounds were in some phase of evaluation or development. ${ }^{19}$ Vaccines have been the focal point of public attention, but $74 \%$ of compounds under study are therapeutics, including antivirals, anti-inflammatory agents, immune stimulators, and respiratory and cardiac therapies that manage lifethreatening COVID-19 symptoms. As these therapies move through reviews by the U.S. Food and Drug Administration and some of them are approved, managed care pharmacy professionals will play a critical role in evaluating their real-world effectiveness and ensuring their appropriate and cost-effective use.

This work must occur in concert with efforts to address health disparities, which have been underscored by the COVID-19 pandemic. Compared to non-Hispanic Whites, rates of COVID-19 infection in Blacks are 2.6 times higher, and rates of death are 2.1 times higher. ${ }^{20}$ Blacks and other people of color also have higher rates of uninsured or underinsured, which is a known barrier to health care access and medication use. ${ }^{21}$ Further, a recent commentary (2020) by Susan Peschin, CEO for the Alliance for Aging Research, asserts that cost-effectiveness models that use quality-adjusted life-years to evaluate health care 
interventions introduce bias by focusing on life expectancy and thereby undervaluing minorities and other populations. ${ }^{22}$

Overcoming access and research challenges because of inequality is critical, but it will not be enough. High copays and other out-of-pocket costs can put effective therapies out of reach for patients of all racial and ethnic backgrounds. AMCP convened a forum, Helping Patients Anticipate and Manage Drug Costs, in March 2020 to address this challenge..$^{23}$ This event-part of AMCP's Partnership Forum series-brought together individuals from managed care, patient advocacy groups, the pharmaceutical industry, and other stakeholders to identify solutions to improve price transparency and help patients better understand and manage drug costs. Their recommendations included strategies to make pharmacy benefits easier to understand, improve predictability of costs, and the "smoothing" of out-of-pocket costs to minimize the effect of high initial costs. More work is needed, but outcomes from this meeting of diverse stakeholders represent initial steps to increasing medication accessibility and affordability for all.

\section{Conclusions}

Managed care pharmacy practice has demonstrated time and time again the ability to improve patient outcomes while also stewarding our scarce health care resources.

The year 2020 marks the 25th anniversary of JMCP and the 32nd anniversary of $\mathrm{AMCP}-$ an association founded to assist its members in efforts to manage drugs and related therapies. Today, this work improves the health of more than 300 million Americans who receive prescription benefits via health plans, pharmacy benefit managers, government-sponsored plans, and emerging models of care. As we look to the future, managed care pharmacy must continue and even expand its dedication to these efforts. Further, it is not enough to improve the effectiveness and safety of drug therapy, we must also increase access, while also containing costs. This is no small challenge, but now is the moment for managed care pharmacy to use its considerable evidence, propensity for innovation, and talent to shine.

\section{DISCLOSURES}

No funding supported the writing of this commentary. The authors have nothing to disclose.

\section{REFERENCES}

1. "inflection point." (n.d.) In MerriamWebster.com. 2020. Accessed September 16, 2020. https://www.merriam-webster. com/dictionary/inflection\%20point

2. Navarro RP. Managed Care Pharmacy Practice. 2nd ed. Jones and Bartlett Publishers; 2009.

3. Bergen E. Pharmacy cost reduction imperative at United HealthCare. J Manag Care Spec Pharm. 1999;5(1):19-20. doi: 10.18553/jmcp.1999.5.1.19

4. Gallup. Prescription drug coverage for older Americans. December 2, 2003. Accessed September 16, 2020. https:// news.gallup.com/poll/9934/prescriptiondrug-coverage-older-americans.aspx

5. Congressional Budget Office. A detailed description of CBO's cost estimate for the Medicare prescription drug benefit. July 2004. Accessed September 16, 2020. https://www.cbo.gov/sites/ default/files/108th-congress-2003-2004/ reports/07-21-medicare.pdf

6. Reichard J. Competition in Part D: is it all it's cracked up to be? The Commonwealth Fund. June 7, 2012. Accessed September 16, 2020. https:// www.commonwealthfund.org/publications/newsletter-article/competitionpart-d-it-all-its-cracked-be
7. Caldwell KA, Edgar B. Moving pharmacy benefits from nice to have to essential benefits. J Manag Care Spec Pharm. 2020;26(8):943-44. doi: 10.18553/ jmcp.2020.26.8.943

8. Brandt NJ, Cooke CE, Sharma K, et. al. Findings from a national survey of Medicare beneficiary perspectives on the Medicare Part D medication therapy management standardized format. J Manag Care Spec Pharm. 2019;25(3):366-91. doi: 10.18553/jmcp.2019.25.3.366

9. AMCP. Comment letter to the Centers for Medicare and Medicaid Services Re: Medication Therapy Management Improvements - Standardized Format (CMS-10396/OMB Control Number 09381154). April 24, 2020. Accessed September 16, 2020. https://www.amcp.org/sites/ default/files/2020-04/AMCP\%20

Comments\%20MTM\%20Standardized\%20 Format.pdf

10. Berwick DM, Nolan TW, Whittington J. The triple aim: care, health, and cost. Health Aff (Millwood). 2008;27(3):759-69.

11. AMCP. AMCP Policy 0401 - Utilization management. February 8, 2017. Accessed September 16, 2020. https://www.amcp. org/policy-advocacy/policy-advocacyfocus-areas/amcp-policy-digest/managed-care-pharmacy-tools

12. Silverman E. Two more big states take aim at PBM pricing practices, which one lawmaker calls 'the wild west' Stat. June 5, 2019. Accessed September 16, 2020. https://www.statnews.com/pharmalot/2019/06/05/pbm-new-york-massachusetts-drug-pricing/

13. Bennett WE. Insurance denials of care amount to unlicensed medical practice. J Manag Care Spec Pharm. 2020;26(7):82224. doi: full/10.18553/jmcp.2020.26.7.822

14. U.S. Government Accountability Office. Medicare Part D, use of pharmacy benefit managers and efforts to manage drug expenditures and utilization. July 2019. Accessed September 16, 2020. https:// www.gao.gov/assets/710/700259.pdf 
15. Garcia MM, Angelini MC, Thomas T, Lenz K, Jeffrey P. Implementation of an opioid management initiative by a state Medicaid program. J Manag Care Spec Pharm. 2014;20(5):447-54. doi: 10.18553/ jmcp.2014.20.5.447

16. AMCP. Brief of the Academy of Managed Care Pharmacy as Amicus Curiae in Support of the Respondent, Leslie Rutledge v. Pharmaceutical Care Management Association. (no. 18-540). Accessed September 16, 2020. https://www.supremecourt.gov/ DocketPDF/18/18-540/139612/202004011 25240046 Academy\%20of\%20 Managed\%20Care\%20Pharmacy\%20 amicus\%20in\%20No.\%2018-540.pdf

17. IQVIA. Medicine use and spending in the U.S. May 9, 2019. Accessed September 16, 2020. https://www.iqvia.com/ insights/the-iqvia-institute/reports/ medicine-use-and-spending-in-the-us-areview-of-2018-and-outlook-to-2023
18. AMCP Partnership Forum: Designing benefits and payment models for innovative high-investment medications. J Manag Care Spec Pharm. 2019;25(2): 156-62. doi: 10.18553/jmcp.2019.25.2.156

19. BIO. COVID-19 Therapeutic Development Tracker. Accessed September 16, 2020. https://www.bio. org/policy/human-health/vaccines-biodefense/coronavirus/pipeline-tracker

20. Centers for Disease Control and Prevention. COVID-19 hospitalization and death by race/ethnicity. August 18, 2020. Accessed September 16, 2020. https:// www.cdc.gov/coronavirus/2019-ncov/ covid-data/investigations-discovery/hospitalization-death-by-race-ethnicity.html
21. Samantha Artiga S, Orgera K, Damico A. Changes in health coverage by race and ethnicity since the ACA, 2010-2018. March 5, 2020. Accessed September 16, 2020. https://www.kff.org/disparities-policy/ issue-brief/changes-in-health-coverage-by-race-and-ethnicity-since-theaca-2010-2018/

22. Peschin S. Cost-effectiveness in health care is racist. Morning Consult. July 6 , 2020. Accessed September 16, 2020. https://morningconsult.com/opinions/ cost-effectiveness-in-health-care-isracist/

23. AMCP Partnership Forum: Helping patients anticipate and manage drug costs. Executive Summary. March 2020. Accessed September 16, 2020. https://www. amcp.org/sites/default/files/2020-04/ PF-MAR2020_ExecSumm_mar27-1.pdf 